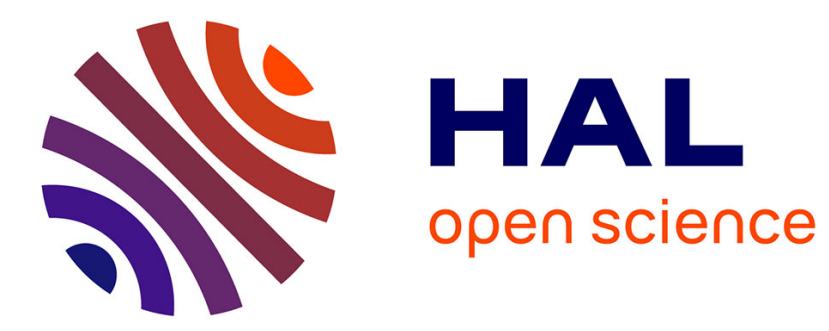

\title{
Cord blood S100B: reference ranges and interest for early identification of newborns with brain injury.
}

Damien Bouvier, Yves Giguère, Bruno Pereira, Nathalie Bernard, Isabelle Marc, Vincent Sapin, Jean-Claude Forest

\section{To cite this version:}

Damien Bouvier, Yves Giguère, Bruno Pereira, Nathalie Bernard, Isabelle Marc, et al.. Cord blood S100B: reference ranges and interest for early identification of newborns with brain injury.. Clinical Chemistry and Laboratory Medicine, 2020, 58 (2), pp.285-293. 10.1515/cclm-2019-0737 . hal03023278

\section{HAL Id: hal-03023278 \\ https://hal.uca.fr/hal-03023278}

Submitted on 4 Jun 2021

HAL is a multi-disciplinary open access archive for the deposit and dissemination of scientific research documents, whether they are published or not. The documents may come from teaching and research institutions in France or abroad, or from public or private research centers.
L'archive ouverte pluridisciplinaire HAL, est destinée au dépôt et à la diffusion de documents scientifiques de niveau recherche, publiés ou non, émanant des établissements d'enseignement et de recherche français ou étrangers, des laboratoires publics ou privés. 


\section{Cord blood S100B: reference ranges and interest for early identification of newborns with brain injury}

4 Damien Bouvier ${ }^{1,2}$, Yves Giguère ${ }^{3,4}$, Bruno Pereira ${ }^{5}$, Nathalie Bernard ${ }^{3}$, Isabelle Marc ${ }^{3,6}$, Vincent

5 Sapin $^{1,2}$, Jean-Claude Forest ${ }^{3,4}$

\section{Affiliations:}

$7 \quad{ }^{1}$ Biochemistry and Molecular Genetic Department, CHU Clermont-Ferrand, Clermont-Ferrand, France;

$8{ }^{2}$ Université Clermont Auvergne, Faculty of medicine, CNRS 6293, INSERM 1103, GReD, Clermont-

9 Ferrand, France;

$10{ }^{3}$ Centre de recherche du CHU de Québec-Université Laval, Québec City, Canada;

$11{ }^{4}$ Department of Molecular Biology, Medical biochemistry and Pathology, Faculty of Medicine, 12 Université Laval, Québec City, Canada;

$13{ }^{5}$ Biostatistics Unit (DRCI), CHU Clermont-Ferrand, Clermont-Ferrand, France;

$14{ }^{6}$ Department of Pediatrics, Faculty of Medicine, Université Laval, Québec City, Canada;

16 Short title: Interest of S100B in cord blood

18 Corresponding author: Damien Bouvier (MD-PhD), Service de Biochimie Médicale, Centre de 19 Biologie, CHU Gabriel Montpied, 58 Rue Montalembert, 63000 Clermont-Ferrand, France Tel.: + 334 73754882 / Fax: + 33473751855 / Email: dbouvier@chu-clermontferrand.fr.

Word count: 3467. 


\section{$1 \quad$ ABSTRACT (244 words)}

Background: Neurological complications are common in the premature and full-term neonates admitted to the intensive care unit, but the diagnosis of these complications is often difficult to make. S100B protein, measured in cord blood, may represent a valuable tool to better identify patients at risk of brain injury.

7 Methods: As a first step, we established S100B cord blood serum reference intervals from 183 preterm 8 and 200 full-term neonates. We then measured cord blood serum S100B to identify neurological 9 complications in 272 neonates hospitalized at the neonatal intensive care unit (NICU). Diagnosis of brain 10 injury relied on imaging examination.

11 Results: The $95^{\text {th }}$ percentiles of $\mathrm{S} 100 \mathrm{~B}$ concentration in cord blood were established as $1.21 \mu \mathrm{g} / \mathrm{L}$ for the 12383 neonates, $0.96 \mu \mathrm{g} / \mathrm{L}$ for full-term neonates, and $1.36 \mu \mathrm{g} / \mathrm{L}$ for premature neonates. Among the 272 13 neonates hospitalized at the NICU, 11 presented neurological complications. Using $1.27 \mu \mathrm{g} / \mathrm{L}$ as the 14 optimal sensitivity/specificity threshold, S100B differentiate neonates with and without neurological 15 complications with a sensitivity of $45.5 \%$ (95\%CI: $16.7-76.6)$ and a specificity of $88.9 \%$ (95\%CI: 84.4$1692.4)(\mathrm{p}=0.006)$. In combination with arterial $\mathrm{pH}(<7.25)$, sensitivity increased to $90.9 \%(95 \% \mathrm{CI}$ : 58.7 17 99.8), while specificity was $51.2 \%(95 \% \mathrm{CI}$ : 44.8-57.7). The sensitivity is significantly $(\mathrm{p}=0.03)$ 18 increased in comparison to S100B alone. The specificity is significantly higher with S100B only than 19 with $\mathrm{pH}+\mathrm{S} 100 \mathrm{~B}(\mathrm{p}<0.001)$.

20 Conclusions: Cord blood S100B protein, in combination with arterial cord blood $\mathrm{pH}$, has the potential to help clinicians to detect at birth neurological complications in neonates hospitalized in a NCIU. 


\section{LIST OF ABBREVIATIONS:}

2

3 AUC: Area Under Curve;

4 CI: confidence interval;

5 GDM: gestational diabetes mellitus

6 GFAP: Glial Fibrillary Acidic Protein ;

7 GH: gestational hypertension

8 HDP: hypertensive disorders of pregnancy

9 HIE: Hypoxic Ischaemic Encephalopathy;

10 IQR: interquartile range;

11 IUGR: intrauterine growth restriction

12 IVH: intraventricular haemorrhage;

13 MRI: magnetic resonance imaging;

14 NICU: Neonatal Intensive Care Unit;

15 PTB: Preterm birth;

16 PVL: periventricular leukomalacia;

17 ROC: receiver operating characteristic;

18 SD: Standard Deviation;

19 UCHL1: Ubiquitin carboxy-terminal hydrolase L1.

20

21

22

23

24

25

26

27

28

29

30

31

32 


\section{INTRODUCTION}

2 Preterm birth (PTB) includes all births before 37 completed weeks of gestation (1) and represents $12 \%$

3 of all births (2). Complications of preterm birth represent the leading cause of death in children younger

4 than 5 years of age, accounting for approximately $16 \%$ of all deaths, and $35 \%$ of deaths among newborn

5 babies (3). Neurological complications, particularly periventricular leukomalacia (PVL), intraventricular

6 haemorrhage (IVH), cerebral palsy, and hypoxic ischaemic encephalopathy (HIE) are common in the

7 premature infant (4)(5), but the diagnosis of these complications is often difficult to establish and rely

8 essentially on clinical observation, arterial $\mathrm{pH}$, and imaging (6)(7)(8). Neurological complications can

9 also be diagnosed in full-term neonates (9). In this context, serum biomarkers, measured in cord blood,

10 represent a potentially useful tool to improve the identification of patients at risk of neurological

11 complications that would need immediate diagnostic measures such as imaging.

12 S100B protein, a small dimeric cytosolic protein $(21 \mathrm{kDa})$ consisting of $\beta \beta$ or $\alpha \beta$ dimers, is well13 established as a sensitive traumatic brain injury biomarker and is therefore a relevant candidate. It is one

14 of the calcium-binding proteins found in glial cells involved in a variety of intracellular and extracellular

15 regulatory activities (10)(11). Following the onset of cerebral lesions, S100B is immediately released

16 from damaged glial cells into the circulation and subsequently eliminated by the kidneys, exhibiting a

17 short half-life of about 30-100 minutes (12)(13)(14). In premature babies, umbilical serum S100B levels

18 were associated with PVL and IVH (13) and cerebral palsy (14). The interest of S100B in detecting HIE

19 has been studied in few small cohorts but the results showed discrepancies (15)(16). S100B protein has

20 been described as a good clinical marker for detecting subdural hematomas in the context of mild

21 traumatic brain injury (17). Of note, serum S100B concentration is high at birth and physiologically

22 decreases during the first years of life with a sex-related change and in correlation with height growth

23 velocity (18). In 58 children (30 terms and 28 premature infants), cord blood S100B concentration was

24 found to be inversely correlated with gestational age at birth (19). Establishing S100B serum 
1 concentration reference values in children has been shown to help the management of mild traumatic

2 brain injury (20). However, S100B reference values in cord blood remain to be determined.

3 The aim of this work is twofold: 1) to establish reference intervals of S100B in cord blood in premature

4 and term neonates and 2) to measure S100B concentration in cord blood as a mean to screen for neurological complications in neonates admitted at the neonatal intensive care unit (NICU).

\section{MATERIALS AND METHODS}

\section{Study design and patients}

9 This is a study of the performance of S100B protein for screening and identifying neonates at risk of

10 neurological complications hospitalized in a NICU, combining biological data and serum cord blood

11 measurement of S100B from an already constituted prospective biobank for which arterial cord blood

12 was collected. At first, we established cord blood serum S100B reference intervals from preterm and full-

13 term infants without neurological complications. Our project took advantage of a research program

14 funded by the CIHR Institute of Human Development, Child and Youth Health Initiative (Grant Number:

15 NRFHPG-78880). An extensive clinical database (environmental, psychosocial, socio-demographic and 16 anthropometric, clinical personal and family history data) was developed with a comprehensive biobank

17 (blood samples including umbilical cord) from pregnant women recruited prospectively from the first

18 trimester/early second trimester and followed during pregnancy. The biobank includes samples from

19 7,866 pregnant women recruited at the CHU de Québec between April 2005 and March 2010 and

20 followed during pregnancy until delivery (21). Participants gave their informed written consent and the

21 study was approved by the Ethics Committee of the CHU de Québec (initial approval date: November 9,

22 2004, project 5-04-10-01 [95.05.17], SC12-01-159). All neonates who were hospitalized in a NICU for

23 which an umbilical cord serum sample stored in the biobank described below were included (case group).

24 This cohort includes 272 babies (3.5\% of the total cohort) hospitalized in a NICU: 84 premature infants 
1 and 188 full-term infants. To establish S100B reference values in cord blood sera from term infants, we

2 selected 200 babies with equal proportions of gender (girls / boys) and mode of delivery (vaginal /

3 caesarean). For these 200 babies, inclusion criteria were: birth after 37 weeks of pregnancy, APGAR

4 score at 1 or 5 min $>8$, duration of labor $<15$ hours (a known criterion for increasing serum S100B level

5 (22)), no pregnancy and delivery complications (hypertensive disorders, gestational diabetes mellitus,

6 abruptio placentae, intrauterine growth restriction, chorioamnionitis, NICU hospitalization). To establish

7 S100B reference values in cord blood sera from premature infants (i.e. delivery $<37$ weeks gestation),

8 all neonates who were premature without neurological complications and had not been hospitalized in a

9 NICU for which an umbilical cord serum sample was stored in the biobank were also included. This

10 group included 183 preterm infants. In total, S100B protein was assayed on 655 samples (272 cases

11 hospitalized in a NICU and 383 controls for reference ranges).

12 Data collection

13 The data collected were: gestational age at birth, maternal age, smoking during pregnancy, hypertensive

14 disorders of pregnancy (HDP), gestational diabetes mellitus (GDM), abruptio placentae, intrauterine

15 growth restriction (IUGR), multiple pregnancies, chorioamnionitis, mode of delivery, use of instrument

16 (forceps, suction cup) during vaginal delivery, gender of newborn, birthweight and length of newborn,

17 head circumference, APGAR scores and blood gas analysis results. Diagnosis of brain injury relied on

18 imaging examination. Diagnosis of hypertensive disorders of pregnancy (HDP) was made by a senior

19 obstetrician according to the classification of the Society of Obstetricians and Gynaecologists of Canada

20 based on information retrieved from medical records, which includes gestational hypertension (GH) and

21 preeclampsia. GH was defined as de novo hypertension (systolic blood pressure $\geq 140 \mathrm{mmHg}$ and/or

22 diastolic blood pressure $\geq 90 \mathrm{mmHg}$ ) after 20 weeks of pregnancy. Preeclampsia was defined as GH with

23 proteinuria ( $\geq 300 \mathrm{mg}$ in a 24 -hour urine collection or $\geq 2+$ on dipstick in a random sample) or pre-existing

24 hypertension and new or worsening proteinuria. Gestational diabetes mellitus (GDM) diagnosis was 
1 established according to the Canadian Diabetes Association 2013 Clinical Practice Guidelines (23).

2 IUGR was defined as birth weight and/or birth length below the $10^{\text {th }}$ percentile for gestational age (24).

3 To check for brain injury, cerebral ultrasound scanning was performed on newborns clinically suspected

4 of brain injury (seizures ...) within $72 \mathrm{~h}$ of birth, and the scan was repeated serially at 7 -d intervals until

5 hospital discharge. If cranial ultrasound showed no structural abnormalities but suspected intracranial

6 lesions, brain magnetic resonance imaging (MRI) examination was performed to confirm the diagnosis

7 of brain injury. Experienced radiologists in neonatal imaging interpreted the neonatal scans. Brain injury

8 included PVL, IVH, HIE, subdural haematoma, stroke, oedema and hydrocephalus. The classification of

9 IVH was as follows: grade 1 (bleeding confined to periventricular area); grade 2 (intraventricular

10 bleeding with $10-50 \%$ of ventricular area); grade 3 (intraventricular bleeding with $>50 \%$ of ventricular

11 area or distended ventricule); grade 4 (periventricular hemorrhagic infarction) (25). HIE was diagnosed

12 by MRI by either white matter injury extending to the cortical areas or deep gray nuclei injury in the

13 basal ganglia or thalamus, or involvement in both areas (26). Neonates with suspect HIE were classified

14 into the 3 categories according to Sarnat stage (mild, moderate, and severe)(27). PVL refers to necrosis

15 of cerebral white matter (8).

\section{Serum S100B measurement}

17 Arterial cord blood samples were processed to serum, aliquoted and deep frozen at $-80{ }^{\circ} \mathrm{C}$ within 2 hours

18 of sampling until assayed. We determined serum S100B concentrations by electro-chemiluminescence

19 immunoassay on a Roche Diagnostics Cobas e602 ${ }^{\circledR}$ instrument (Roche Diagnostics, Laval, Canada). The

20 S100B calibration curve is linear up to $39 \mu \mathrm{g} / \mathrm{L}$, and the coefficient of variation for duplicates across the

21 entire concentration range for calibrators and samples was 3.1\%. The lower limit of detection of the assay

22 was set at $0.005 \mu \mathrm{g} / \mathrm{L}$, as given in the manufacturer's instructions. As S100B measurement has been

23 performed retrospectively, the results of S100B had no effect on the clinical management of the neonates. 


\section{$1 \quad$ Statistics}

2 Sample size for determination of S100B reference values was calculated according to Gazzolo et al. (19)

3 which reports standard-deviation (SD) of cord blood S100B concentrations ranging between 0.35 and

$4 \quad 0.64 \mu \mathrm{g} / \mathrm{L}$. Using this SD, it was considered that at least 350 patients were needed to highlight an effect-

5 size greater than 0.3 (i.e. a between-groups difference around 0.10 for $\mathrm{SD}=0.35$ ) for a two-sided type I

6 error of $5 \%$ and a statistical power greater than $80 \%$.

7 The categorical variables were presented as numbers and associated percentages, whereas the continuous

8 variables were expressed as mean \pm standard deviations, or median and interquartile range (IQR) and

9 range (minimum - maximum). The normality assumption was assessed graphically and using the

10 Shapiro-Wilk's test. For the control group used to establish reference ranges, the $95^{\text {th }}$ percentile was also

11 calculated. To study the relationships between quantitative parameters, correlation coefficients (Pearson

12 or Spearman according to the statistical distribution) were calculated. The comparisons between groups

13 (case versus control group) were carried out using the Chi-squared test or Fisher's exact test when

14 appropriate, for categorical data, and using the Student's t-test or the Mann-Whitney's test when the

15 assumptions of t-test were not met for continuous data. In control group, the comparisons concerning

16 S100B according to gestational age, gender of neonate, mode of delivery, smoking during pregnancy and

17 presence of neonatal jaundice were performed with same inferential statistical tests. Multivariable

18 analysis was carried out using multiple linear regression with logarithmic S100B as the dependent

19 outcome and the following covariates: IUGR, GDM, HDP, maternal age, use of instrument during

20 delivery, parity, gestational age at birth, gender, mode of delivery, placenta abruptio, smoking during

21 pregnancy and neonatal jaundice. For the comparison between patients with and without brain injuries,

22 the best threshold of S100B and arterial $\mathrm{pH}$ was determined by ROC curve analysis estimating usual

23 Youden and Liu indexes. Area under the curve (AUC), sensitivity, specificity, positive and negative

24 values were calculated and presented with $95 \%$ confidence intervals $(95 \% \mathrm{CI})$. The results were 
1 graphically presented with forest-plots. Sensitivity and specificity of S100B and arterial $\mathrm{pH}$ were

2 compared using McNemar's test for paired proportions. Then, the combination of S100B and arterial $\mathrm{pH}$

3 was developed, studying these two parameters as continuous or binary variables according to cut-off

4 determined as described before. To conclude, multivariable analysis using exact logistic regression

5 model was performed to study the association between brain injuries and the combination of S100B and

6 arterial $\mathrm{pH}(\mathrm{S} 100 \mathrm{~B}+\mathrm{pH})$ adjusting for covariates fixed according to univariate results and to their clinical

7 relevance: smoking during pregnancy, gestational age at birth, mode of delivery, GDM, HDP, IUGR,

8 multiple pregnancy, chorioamnionitis, maternal age and placenta abruptio. Attention was paid on the

9 study of interactions between significant factors and on the presence of multicollinearity. The model was

10 validated by a two-step bootstrapping process. For each step, bootstrap samples with replacements

$11(n=1000)$ were generated from the training set. In the first phase, the percentage of models including each

12 initial variable was determined by usual stepwise approach. Then, in the second phase, parameters of

13 generalized linear regression (exact logistic regression) of the final model were independently estimated.

14 The bootstrap estimates associated to each covariate regression coefficient, and their associated standard

15 errors, were finally averaged from replicates. Statistical analyses were carried out using STATA software

16 (version 12, StataCorp, College Station, US). A two-sided p value of less than 0.05 was considered to

17 indicate statistical significance.

\section{RESULTS}

\section{Patients and serum S100B median concentrations}

21 In the case group, 272 neonates who were hospitalized in a NICU, included 84 premature infants and

22188 full-term infants. In control group (to establish S100B reference values for cord blood sera), 383

23 neonates were selected: 200 full-term neonates and 183 preterm infants (Table 1). The proportion of 24 neonates from multiple pregnancies was significantly higher in the case group than in the control group 
$1 \quad(14 \%$ and $4.4 \%$ respectively, $\mathrm{p}<0.0001)$ (Table 1$)$. Cases weighed significantly less than neonates from

2 the control group (3068 g (min: 660, max: 5118, IQR: 2537-3528) and $3155 \mathrm{~g}$ (min: 1856, max: 4676,

3 IQR: 2719-3548) respectively, $\mathrm{p}=0.02)($ Table 1 ). The median head circumference was significantly

$4(p=0.002)$ smaller among cases $(33.5$ ( $\min : 26$, max: 39, IQR: 32-34.6)) than controls (34 (min: 28, max: 49, IQR: 33-35))(Table 1). Arterial and venous $\mathrm{pH}$ were significantly ( $\mathrm{p}=0.002$ and 0.003 respectively) lower in cases (7.27 and 7.33 respectively) than in controls (7.29 and 7.35 respectively)(Table 1$)$. The case group median concentration of S100B was $0.51 \mu \mathrm{g} / \mathrm{L}$ (min: 0.16 , max: 11.48, IQR: 0.36-0.82), while the control group median concentration of S100B was $0.37 \mu \mathrm{g} / \mathrm{L}$ (min: 0.08, max: 5.64, IQR: 0.29-0.54). The differences between these 2 groups were statistically significant $(\mathrm{p}<0.001)($ Table 1$)$.

\section{Reference ranges for S100B cord blood serum in control group}

12 The control group median concentration of $\mathrm{S} 100 \mathrm{~B}$ was $0.37 \mu \mathrm{g} / \mathrm{L}$ ( $\min : 0.08$, max: 5.64, IQR: 0.29-

13 0.54)(Table 1). There were no significant differences in S100B median concentration according to gender 14 of neonate $(\mathrm{p}=0.66)$, smoking during pregnancy $(\mathrm{p}=0.87)$, presence of neonatal icteria $(\mathrm{p}=0.07)$ and parity $15(\mathrm{p}=0.67)($ Table2). With multivariable analysis, the parity has a significant impact on the S100B 16 concentration $(\mathrm{p}=0.04)($ Table 2$)$. Cord blood $\mathrm{S} 100 \mathrm{~B}$ concentration was found to be inversely correlated 17 with gestational age at delivery $(\mathrm{r}=-0.22, \mathrm{p}<0.001)$ and was significantly higher in premature neonates 18 than in full-term neonates $(0.42$ and $0.34 \mu \mathrm{g} / \mathrm{L}$ respectively, $\mathrm{p}<0.001))($ Table 2$)$. In premature neonates, 19 there was no significantly difference $(\mathrm{p}=0.11)$ of S100B concentration between gestational age 20 subgroups $(34-35$ weeks $(n=13), 35-36$ weeks $(n=35), 36-37$ weeks $(n=135))$. S100B median 21 concentration was significantly different according to the mode of delivery being greater vaginal delivery $22(\mathrm{p}<0.001)($ Table 2$)$. With multivariable analysis, the effect of the delivery mode on the S100B 23 concentration is no longer significant mainly because of the criterion "use of instrument". Indeed, S100B 24 median concentration was significantly different according to the use of instrument (forceps, suction cup) 
1 during vaginal delivery $(\mathrm{p}<0.001)$ (Table 2$)$. The maximum normal serum S100B reference level $\left(95^{\text {th }}\right.$

2 percentile) was $1.21 \mu \mathrm{g} / \mathrm{L}$ for the whole control group, $0.96 \mu \mathrm{g} / \mathrm{L}$ for the full-term subgroup and 1.36 $3 \mu \mathrm{g} / \mathrm{L}$ for the premature subgroup (Table 2).

\section{S100B, arterial pH and neurological complications in case group}

6 In the case group, 16 neonates (5.9\%) presented a neurological complication (Table 1$)$. The 5 patients

7 with IVH were all with a grade 1 and all evolved satisfactorily without interventions and were promptly

8 discharge from the NICU. For the following analyses, they were removed from the subgroup of cases

9 with neurological complications.

10 The best threshold using Youden and Liu indexes was $>1.27 \mu \mathrm{g} / \mathrm{L}$ for S100B and $<7.25$ for arterial $\mathrm{pH}$.

11 Using a threshold of $1.27 \mu \mathrm{g} / \mathrm{L}$, we observed a significant capacity ( $\mathrm{p}=0.006$ ) of S100B to differentiate 12 neonates with and without neurological complications with an AUC of 0.67 (95\%CI: 0.52-0.83)(Figure 13 1), a sensitivity of $45.5 \%$ (95\%CI: 16.7-76.6), a specificity of $88.9 \%$ (95\%CI: 84.4-92.4), and a negative 14 predictive value of 97.5\% (95\%CI: 94.6-99.1)(Figure 2).

15 Using a threshold of 7.25 , we observed a significant capacity $(\mathrm{p}=0.046)$ of arterial $\mathrm{pH}$ to differentiate 16 neonates with and without neurological complications with an AUC of 0.68 (95\%CI: 0.55-0.82)(Figure 17 1), a sensitivity of $80 \%$ (95\%CI: 44.4-97.5), a specificity of 56.6\% (95\%CI: $52.1-62.9)$, and a negative 18 predictive value of $98.6 \%$ (95\%CI: 94.9-99.8)(Figure 2).

19 After combining S100B and arterial $\mathrm{pH}$, we observed a significant capacity $(\mathrm{p}=0.01)$ of the bivariate 20 model to differentiate neonates with and without neurological complications with an AUC of 0.76 21 (95\%CI: 0.62-0.90)(Figure 1), a sensitivity of 90.9\% (95\%CI: $58.7-99.8)$, a specificity of $51.2 \%(95 \% \mathrm{CI}$ : 22 44.8-57.7), a negative predictive value of 99.4\% (95\%CI: 95.7-100)(Figure 2). The sensitivity is 23 significantly $(\mathrm{p}=0.03$ ) increased in comparison to $\mathrm{S} 100 \mathrm{~B}$ alone, but not to arterial $\mathrm{pH}$, while the 24 specificity is significantly higher with $\mathrm{S} 100 \mathrm{~B}$ alone than with $\mathrm{pH}$ alone $(\mathrm{p}<0.001)$ or $\mathrm{pH}+\mathrm{S} 100 \mathrm{~B}$ 
$1(\mathrm{p}<0.001)($ Figure 2). The diagnostic performance of the S100B seems excellent for diagnosing

2 periventricular leukomalacia with values at 1.67 and $11.48 \mu \mathrm{g} / \mathrm{L}$ (Table 3).

3 Exact logistic regression multivariable analysis applying a bootstrap procedure confirmed the association

4 between brain injuries and the combination of S100B and arterial $\mathrm{pH}$ in cord blood, independently from

5 smoking during pregnancy, gestational age birth, mode of delivery, GDM, HDP, IUGR, multiple

6 pregnancy, chorioamnionitis, maternal age and placenta abruptio $(\mathrm{p}=0.03)$.

8 DISCUSSION

10 Our prospective study, based on 655 neonates, demonstrates the potential interest of measuring S100B

11 protein cord blood concentrations for the management of neonates hospitalized in a NCIU. This is the

12 first study to report reference ranges for serum S100B protein in cord blood that, as of yet, is the largest 13 published population of healthy neonates.

14 In the 383 neonates from the control group, the $95^{\text {th }}$ percentile of S100B concentration in cord blood was 15 established as $1.21 \mu \mathrm{g} / \mathrm{L}$, which is higher than the $95^{\text {th }}$ percentile S100B values reported for children aged 16 under 4 months $(0.51 \mu \mathrm{g} / \mathrm{L})$ using the same technology (28). As was previously observed, in a cohort of 1758 children (19), cord blood S100B concentration was found to be inversely correlated with gestational 18 age at birth. The serum S100B reference levels $\left(95^{\text {th }}\right.$ percentile) were derived for 2 gestational age groups: $190.96 \mu \mathrm{g} / \mathrm{L}$ for full-term neonates $(\geq 37$ weeks); $1.36 \mu \mathrm{g} / \mathrm{L}$ for premature neonates $(<37$ weeks). We 20 confirmed an effect of the mode of delivery on S100B serum concentrations as previously described by 21 Schulpis et al. (22). However, unlike this previous study, we showed that this difference is found even 22 when the duration of labor is $<15$ hours. The evidence of this effect is probably explained by the size of 23 our cohort (146 caesarean deliveries and 237 vaginal deliveries in our cohort against 22 and 20 24 respectively by Schulpis et al). After multivariate analysis, this effect is probably more related to the use 25 of instruments (forceps, suction cup) during vaginal delivery than to the delivery mode itself. Indeed, we 
1 have highlighted a significant link between the use of instrument and the elevation of S100B

2 serum concentrations. We did not find any impact of neonatal jaundice or maternal smoking on the

3 S100B concentration in the cord blood but we observed an impact of parity. Furthermore, we did not find

4 any association with smoking, which contradicts a previous study (29). The effect of gender was not observed. Gazzolo et al. highlighted a sex-related change of pediatrics concentrations of S100B protein

6 in blood in a large cohort of 1004 children aged 0-15 years. Note, however, that this difference was not

7 significant in the subgroup of children aged 0 to 2 years (18). A sex-related change of $0.01 \mu \mathrm{g} / \mathrm{L}$ was

8 also observed in maternal blood in third trimester (30).

9 Among the 272 neonates from the case group necessitating admission at the NICU, the threshold

10 combining the best compromise of sensitivity / specificity to differentiate neonates with and without

11 neurological complications was $1.27 \mu \mathrm{g} / \mathrm{L}$ for $\mathrm{S} 100 \mathrm{~B}$, which validates our upper reference value of 1.21

$12 \mu \mathrm{g} / \mathrm{L}$ determined from the control group. The sensitivity of $45.5 \%$ is significantly increased to $90.9 \%$

13 when combining S100B to arterial cord blood $\mathrm{pH}$ which is already routinely determined. The only case

14 of a false negative result, which showed a slight subdural hematoma of the cerebellum, did not present

15 any aggravation during hospitalization. A link between high S100B and decreased $\mathrm{pH}$ in cord blood has

16 recently been observed in another context (31). We demonstrate here a complementarity of these two

17 biological parameters. The S100B protein alone is however more specific, which is understandable in

18 view of its cellular origin (10). However, Roche Diagnostics instruments dose both of $\beta \beta$ or $\alpha \beta$ dimers

19 and only $\beta \beta$ dimer is strongly expressed by the nervous system (32). In view of these results, one could

20 consider an algorithm using cord blood S100B coupled to the arterial cord blood pH to improve

21 sensitivity and to reduce the occurrence of false positive results. S100B appears to be an interesting

22 candidate predictor of PVL at birth. For the other complications (hydrocephalus, HIE, subdural

23 haematoma, stroke, oedema), sensitivity can be improved at birth, i.e. potentially 1-2 days before 
1 neurological complication, after combination with arterial $\mathrm{pH}$, or by serial measurements over time or at

2 the onset of clinical symptoms as described in others studies (33). The latter has yet to be demonstrated.

3 The low number of neurological complications and their heterogeneity represent a constraint to the

4 generalization of our study and need to be confirmed. However, exact logistic regression multivariable

5 analysis applying a bootstrap procedure confirmed the association between brain injuries and the

6 combination of S100B and arterial $\mathrm{pH}$ in cord blood and is a strength of our work.

7 The diagnostic performance of S100B could possibly be further improved by combining S100B with 8 other potential biomarkers of brain injury, namely glial fibrillary acidic protein (GFAP) or ubiquitin c-

9 terminal hydrolase-L1 (UCH-L1). The interest of GFAP and UCHL1 in detecting HIE has been studied 10 in small cohorts of children but the results were discrepant (34)(35)(36).

11 In conclusion, we provided reference values of S100B protein in cord blood and showed that the 12 diagnostic performance of S100B in combination with arterial cord blood $\mathrm{pH}$ has the potential to help 13 clinicians to predict at birth the occurrence of neurological complication in at-risk neonates hospitalized 14 in a NCIU. 
1 Acknowledgements: The authors thank the research nurses for the recruitment of participants and

2 retrieval of data from the medical records and Alexandra Castillo for S100B dosages. This work was

3 supported by the Canadian Institutes of Health Research (CIHR, Healthy Pregnancy Initiative from the

4 Institute for Human Development, Child and Youth Health, Grant number: NRFHPG-78880). The 5 authors thank Roche Diagnostics (Laval, Canada) for providing the s100 kits. The funders had no role in 6 study design, data collection and analysis, decision to publish, or preparation of the manuscript. 


\section{REFERENCES}

1. WHO: recommended definitions, terminology and format for statistical tables related to the perinatal period and use of a new certificate for cause of perinatal deaths. Modifications recommended by FIGO as amended October 14, 1976. Acta Obstet Gynecol Scand. 1977;56(3):247-53.

2. Martin JA, Hamilton BE, Sutton PD, Ventura SJ, Mathews TJ, Kirmeyer S, et al. Births: final data for 2007. Natl Vital Stat Rep. 2010 Aug 9;58(24):1-85.

3. Chawanpaiboon S, Vogel JP, Moller A-B, Lumbiganon P, Petzold M, Hogan D, et al. Global, regional, and national estimates of levels of preterm birth in 2014: a systematic review and modelling analysis. Lancet Glob Health. 2019 Jan;7(1):e37-e46.

4. Kinney HC. The near-term (late preterm) human brain and risk for periventricular leukomalacia: a review. Semin Perinatol. 2006 Apr;30(2):81-8.

5. Ramenghi LA. Late preterm babies and the risk of neurological damage. Acta Biomed. 2015 Jun 29;86 Suppl 1:36-40.

6. Al-Abdi SY, Al-Aamri MA. A Systematic Review and Meta-analysis of the Timing of Early Intraventricular Hemorrhage in Preterm Neonates: Clinical and Research Implications. J Clin Neonatol. 2014 Apr;3(2):76-88.

7. Gopagondanahalli KR, Li J, Fahey MC, Hunt RW, Jenkin G, Miller SL, et al. Preterm HypoxicIschemic Encephalopathy. Front Pediatr. 2016 Oct 20;4:114.

8. Volpe JJ. Brain injury in the premature infant: overview of clinical aspects, neuropathology, and pathogenesis. Semin Pediatr Neurol. 1998 Sep;5(3):135-51.

9. Triulzi F, Parazzini C, Righini A. Patterns of damage in the mature neonatal brain. Pediatr Radiol. $2006 \mathrm{Jul} ; 36(7): 608-20$.

10. Zimmer DB, Cornwall EH, Landar A, Song W. The S100 protein family: history, function, and expression. Brain Res Bull. 1995;37(4):417-29.

11. Donato R. S100: a multigenic family of calcium-modulated proteins of the EF-hand type with intracellular and extracellular functional roles. Int J Biochem Cell Biol. 2001 Jul;33(7):637-68.

28 12. Petzold A, Keir G, Lim D, Smith M, Thompson EJ. Cerebrospinal fluid (CSF) and serum S100B: 29 release and wash-out pattern. Brain Res Bull. 2003 Aug 15;61(3):281-5.

30 13. Lu H, Huang W, Chen X, Wang Q, Zhang Q, Chang M. Relationship between premature brain

31 injury and multiple biomarkers in cord blood and amniotic fluid. J Matern Fetal Neonatal Med. 2018 32 Nov;31(21):2898-904.

33 14. Costantine MM, Weiner SJ, Rouse DJ, Hirtz DG, Varner MW, Spong CY, et al. Umbilical cord 34 blood biomarkers of neurologic injury and the risk of cerebral palsy or infant death. Int J Dev 35 Neurosci. 2011 Dec;29(8):917-22

36 15. Summanen M, Seikku L, Rahkonen P, Stefanovic V, Teramo K, Andersson S, et al. Comparison 37 of Umbilical Serum Copeptin Relative to Erythropoietin and S100B as Asphyxia Biomarkers at Birth. 38 Neonatology. 2017;112(1):60-6.

39 16. Zaigham M, Lundberg F, Olofsson P. Protein S100B in umbilical cord blood as a potential biomarker of hypoxic-ischemic encephalopathy in asphyxiated newborns. Early Hum Dev. 2017 Sep;112:48-53.

17. Bouvier D, Fournier M, Dauphin J-B, Amat F, Ughetto S, Labbe A, et al. Serum S100B determination in the management of pediatric mild traumatic brain injury. Clin Chem. 2012 $\mathrm{Jul} ; 58(7): 1116-22$.

18. Gazzolo D, Michetti F, Bruschettini M, Marchese N, Lituania M, Mangraviti S, et al. Pediatric concentrations of S100B protein in blood: age- and sex-related changes. Clin Chem. 2003 Jun;49(6 Pt 1):967-70.

48 19. Gazzolo D, Vinesi P, Marinoni E, Di Iorio R, Marras M, Lituania M, et al. S100B protein 
concentrations in cord blood: correlations with gestational age in term and preterm deliveries. Clin Chem. 2000 Jul;46(7):998-1000.

20. Oris C, Pereira B, Durif J, Simon-Pimmel J, Castellani C, Manzano S, et al. The Biomarker S100B and Mild Traumatic Brain Injury: A Meta-analysis. Pediatrics. 2018 Jun;141(6).

21. Forest J-C, Theriault S, Masse J, Bujold E, Giguere Y. Soluble Fms-like tyrosine kinase-1 to placental growth factor ratio in mid-pregnancy as a predictor of preterm preeclampsia in asymptomatic pregnant women. Clin Chem Lab Med. 2014 Aug;52(8):1169-78.

22. Schulpis KH, Margeli A, Akalestos A, Vlachos GD, Partsinevelos GA, Papastamataki M, et al. Effects of mode of delivery on maternal-neonatal plasma antioxidant status and on protein S100B serum concentrations. Scand J Clin Lab Invest. 2006;66(8):733-42.

23. Agarwal MM. Gestational diabetes mellitus: An update on the current international diagnostic criteria. World J Diabetes. 2015 Jun 25;6(6):782-91.

24. Wollmann HA. Intrauterine growth restriction: definition and etiology. Horm Res. 1998;49 Suppl 2:1-6.

25. Papile LA, Burstein J, Burstein R, Koffler H. Incidence and evolution of subependymal and intraventricular hemorrhage: a study of infants with birth weights less than 1,500 gm. J Pediatr. 1978 Apr;92(4):529-34.

26. Shankaran S, McDonald SA, Laptook AR, Hintz SR, Barnes PD, Das A, et al. Neonatal Magnetic Resonance Imaging Pattern of Brain Injury as a Biomarker of Childhood Outcomes following a Trial of Hypothermia for Neonatal Hypoxic-Ischemic Encephalopathy. J Pediatr. 2015 Nov;167(5):987-993.e3.

27. Sarnat HB, Sarnat MS. Neonatal encephalopathy following fetal distress. A clinical and electroencephalographic study. Arch Neurol. 1976 Oct;33(10):696-705.

28. Simon-Pimmel J, Lorton F, Masson D, Bouvier D, Hanf M, Gras-Le Guen C. Reference ranges for serum S100B neuroprotein specific to infants under four months of age. Clin Biochem. 2017 Dec;50(18):1056-60.

29. Kahyaoglu I, Kayikcioglu F, Gucel F, Demirtas C, Ozdemirci S, Mollamahmutoglu L. Umbilical CORD S100B levels in active and passive smoker women. Eur Rev Med Pharmacol Sci. 2014;18(5):723-7.

29 30. Serpero LD, Bianchi V, Pluchinotta F, Conforti E, Baryshnikova E, Guaschino R, et al. S100B 30 maternal blood levels are gestational age- and gender-dependent in healthy pregnancies. Clin Chem Lab 31 Med. 2017 Oct 26;55(11):1770-6.

32 31. Irmak K, Tuten N, Karaoglu G, Madazli R, Tuten A, Malik E, et al. Evaluation of cord blood creatine kinase $(\mathrm{CK})$, cardiac troponin $\mathrm{T}(\mathrm{cTnT}), \mathrm{N}$-terminal-pro-B-type natriuretic peptide (NTproBNP), and s100B level in nonreassuring foetal heart rate. J Matern Fetal Neonatal Med. 2019 Jun 25:1-6.

32. Jackson P, Thompson RJ. The demonstration of new human brain-specific proteins by highresolution two-dimensional polyacrylamide gel electrophoresis. J Neurol Sci. 1981 Mar;49(3):429-38.

33. Serpero LD, Pluchinotta F, Gazzolo D. The clinical and diagnostic utility of S100B in preterm newborns. Clin Chim Acta. 2015 Apr 15;444:193-8.

34. Chalak LF, Sanchez PJ, Adams-Huet B, Laptook AR, Heyne RJ, Rosenfeld CR. Biomarkers for severity of neonatal hypoxic-ischemic encephalopathy and outcomes in newborns receiving hypothermia therapy. J Pediatr. 2014 Mar;164(3):468-474.e1.

35. Zaigham M, Lundberg F, Hayes R, Unden J, Olofsson P. Umbilical cord blood concentrations of ubiquitin carboxy-terminal hydrolase L1 (UCH-L1) and glial fibrillary acidic protein (GFAP) in neonates developing hypoxic-ischemic encephalopathy. J Matern Fetal Neonatal Med. 2016;29(11):1822-8.

36. Looney A-M, Ahearne C, Boylan GB, Murray DM. Glial Fibrillary Acidic Protein Is Not an Early Marker of Injury in Perinatal Asphyxia and Hypoxic-Ischemic Encephalopathy. Front Neurol. 2015;6:264. 
3 TABLE 1

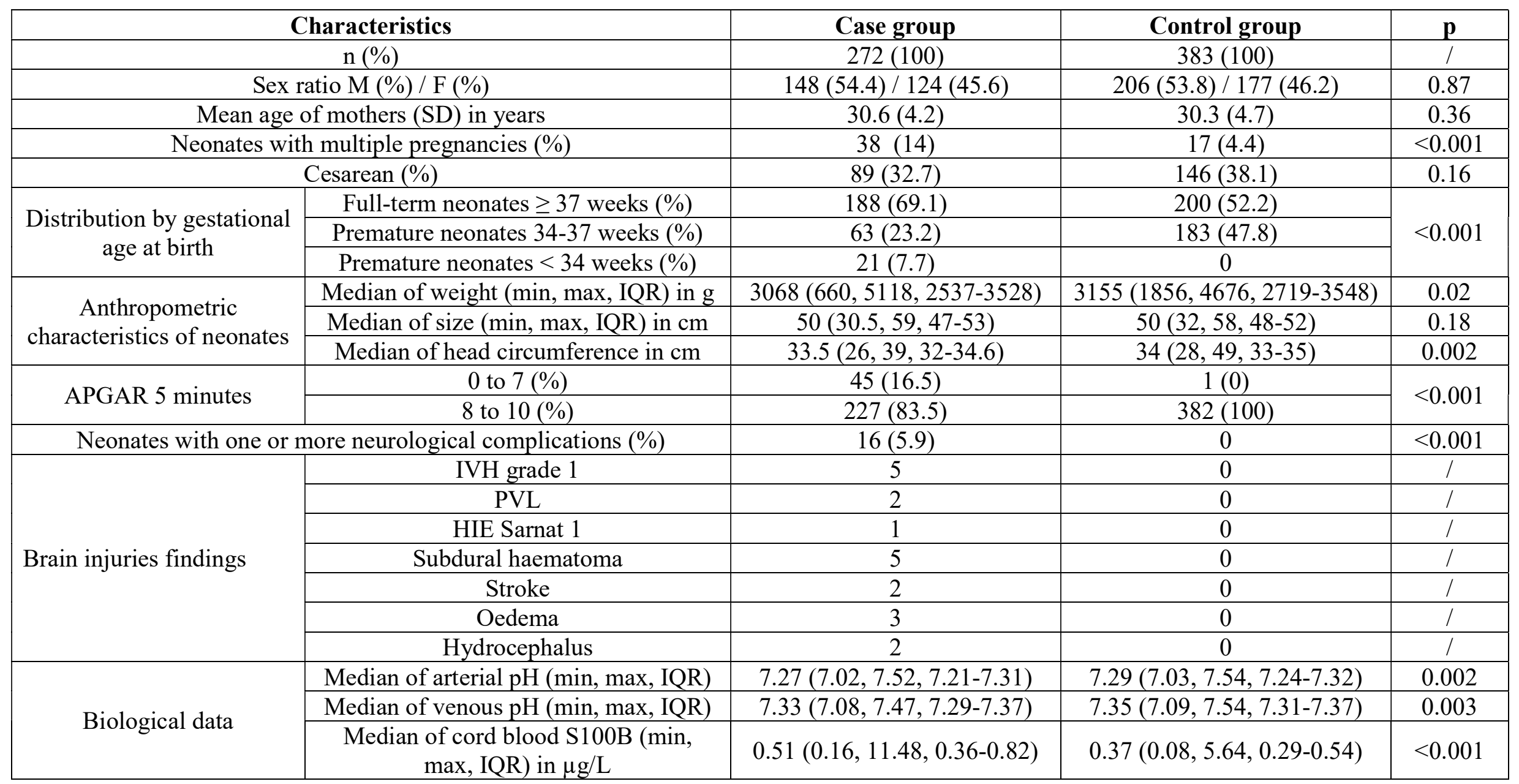

4 
3 TABLE 2

\begin{tabular}{|c|c|c|c|c|c|c|c|}
\hline \multirow{2}{*}{\multicolumn{2}{|c|}{ Group }} & \multirow[b]{2}{*}{$\mathbf{n}$} & \multicolumn{3}{|c|}{$\mathrm{S100B}$ in $\mu \mathrm{g} / \mathrm{L}$} & \multirow[b]{2}{*}{$\mathbf{p}^{1}$} & \multirow[b]{2}{*}{$\mathbf{p}^{2}$} \\
\hline & & & Median & IQR & $\begin{array}{c}95^{\text {th }} \\
\text { percentile }\end{array}$ & & \\
\hline \multicolumn{2}{|c|}{ Total } & 383 & 0.37 & $0.29-0.54$ & 1.21 & 1 & 1 \\
\hline \multirow{2}{*}{$\begin{array}{l}\text { According to gestationnel } \\
\text { age }\end{array}$} & Full-term neonates $\geq 37$ weeks & 200 & 0.34 & $0.26-0.45$ & 0.96 & \multirow{2}{*}{$<0.001$} & \multirow{2}{*}{0.02} \\
\hline & Premature neonates $<37$ weeks & 183 & 0.42 & $0.32-0.62$ & 1.36 & & \\
\hline \multirow{2}{*}{$\begin{array}{c}\text { According to gender of } \\
\text { neonate }\end{array}$} & Female & 177 & 0.37 & $0.31-0.54$ & 1.17 & \multirow{2}{*}{0.66} & \multirow{2}{*}{0.53} \\
\hline & Male & 206 & 0.37 & $0.28-0.54$ & 1.27 & & \\
\hline \multirow{2}{*}{$\begin{array}{l}\text { According to the mode of } \\
\text { delivery }\end{array}$} & Cesarean delivery & 146 & 0.34 & $0.25-0.44$ & 0.83 & \multirow{2}{*}{$<0.001$} & \multirow{2}{*}{0.54} \\
\hline & Vaginal delivery & 237 & 0.40 & $0.32-0.59$ & 1.27 & & \\
\hline \multirow{2}{*}{$\begin{array}{l}\text { According to smoking } \\
\text { during pregnancy }\end{array}$} & Non-smoking mother & 319 & 0.37 & $0.29-0.54$ & 1.26 & \multirow{2}{*}{0.87} & \multirow{2}{*}{0.05} \\
\hline & Smoking mother & 50 & 0.36 & $0.28-0.54$ & 1.17 & & \\
\hline \multirow{2}{*}{$\begin{array}{c}\text { According to the presence } \\
\text { of neonatal jaundice }\end{array}$} & Absence & 305 & 0.36 & $0.28-0.51$ & 1.16 & \multirow{2}{*}{0.07} & \multirow{2}{*}{0.70} \\
\hline & Presence & 55 & 0.42 & $0.30-0.65$ & 1.17 & & \\
\hline \multirow{2}{*}{ According to parity } & Nulliparity & 173 & 0.40 & $0.29-0.56$ & 1.09 & \multirow{2}{*}{0.67} & \multirow{2}{*}{0.04} \\
\hline & Multiparity & 210 & 0.36 & $0.28-0.53$ & 1.27 & & \\
\hline \multirow{2}{*}{$\begin{array}{l}\text { According to the use of } \\
\text { instrument (forceps, suction } \\
\text { cup) during vaginal delivery }\end{array}$} & No use & 190 & 0.37 & $0.30-0.54$ & 0.57 & \multirow{2}{*}{$<0.001$} & \multirow{2}{*}{0.002} \\
\hline & Use & 30 & 0.55 & $0.44-0.94$ & 1.02 & & \\
\hline
\end{tabular}


3 TABLE 3

\begin{tabular}{|c|c|c|c|c|c|c|c|c|c|c|c|}
\hline \multirow[b]{2}{*}{ Patient } & \multirow[b]{2}{*}{ Sexe } & \multirow{2}{*}{$\begin{array}{l}\text { Gestational age } \\
\text { at delivery }\end{array}$} & \multirow{2}{*}{$\begin{array}{l}\text { Mode of } \\
\text { delivery }\end{array}$} & \multicolumn{6}{|c|}{ Brain injuries } & \multirow[b]{2}{*}{$\begin{array}{l}\text { S100B } \\
(\mu \mathrm{g} / \mathrm{L})\end{array}$} & \multirow[b]{2}{*}{$\begin{array}{c}\text { Arterial } \\
\text { pH }\end{array}$} \\
\hline & & & & PVL & Hydrocephalus & HIE & $\begin{array}{c}\text { Subdural } \\
\text { haematoma }\end{array}$ & Stroke & Oedema & & \\
\hline 1 & $\mathrm{M}$ & 37.29 & vaginal & 0 & 1 & 0 & 1 & 0 & 0 & 0.20 & 7.24 \\
\hline 2 & $\mathrm{~F}$ & 39.71 & vaginal & 0 & 0 & 1 & 0 & 0 & 1 & 0.45 & 7.23 \\
\hline 3 & $\mathrm{M}$ & 38 & vaginal & 0 & 0 & 0 & 1 & 0 & 0 & 0.48 & 7.35 \\
\hline 4 & $\mathrm{~F}$ & 41.14 & cesarean & 0 & 0 & 0 & 0 & 1 & 1 & 0.57 & 7.25 \\
\hline 5 & $\mathrm{~F}$ & 40.86 & vaginal & 0 & 0 & 0 & 1 & 0 & 0 & 0.59 & 7.12 \\
\hline 6 & $\mathrm{M}$ & 38.86 & vaginal & 0 & 0 & 0 & 1 & 0 & 0 & 0.67 & 7.08 \\
\hline 7 & $\mathrm{M}$ & 40.71 & cesarean & 0 & 0 & 0 & 0 & 0 & 1 & 1.27 & 7.02 \\
\hline 8 & $\mathrm{~F}$ & 40.57 & vaginal & 0 & 1 & 0 & 0 & 0 & 0 & 1.34 & 7.28 \\
\hline 9 & $\mathrm{M}$ & 33.29 & vaginal & 1 & 0 & 0 & 0 & 0 & 0 & 1.36 & I \\
\hline 10 & $\mathrm{M}$ & 40 & vaginal & 0 & 0 & 0 & 0 & 1 & 0 & 1.67 & 7.06 \\
\hline 11 & $\mathrm{~F}$ & 39 & vaginal & 1 & 0 & 0 & 1 & 0 & 0 & 11.48 & 7.21 \\
\hline
\end{tabular}

4

5

6

7

8 


\section{FIGURES AND TABLES LEGEND}

Table 1: Clinical and biological characteristics of the cohort. All neonates from the case group were hospitalized in a neonatal intensive care unit. A two-sided $p$ value of less than 0.05 was considered to indicate statistical significance. IVH: intraventricular haemorrhage; HIE: hypoxic ischaemic encephalopathy; IQR: interquartile range; PVL: periventricular leukomalacia.

Table 2: Cord blood S100B levels and distribution in neonates from control group. Serum S100B concentrations are shown according to different condition defined by the number of samples (n), median, interquartile range (IQR) and $95^{\text {th }}$ percentile. $\mathrm{p}^{1}$ : Mann and Whitney test; $\mathrm{p}^{2}$ : Multivariate analysis with intrauterine growth restriction, gestational diabetes mellitus, hypertensive disorders of pregnancy, maternal age, use of instrument during delivery, parity, gestational age at birth, gender, mode of delivery, placenta abruptio, smoking during pregnancy and neonatal jaundice. A two-sided $p$ value of less than 0.05 was considered to indicate statistical significance.

Figure 1: ROC curve of S100B $(>1.27 \mu \mathrm{g} / \mathrm{L})$, arterial $\mathrm{pH}(<7.25)$ and $\mathrm{S} 100 \mathrm{~B}+\mathrm{pH}(>1.27 \mu \mathrm{g} / \mathrm{L}$ and/or $<7.25$ respectively) measurements in cord blood for the discrimination of neurological complications in neonates hospitalized in a neonatal intensive care unit (case group). The areas under the curve are expressed with $95 \%$ confidence intervals.

Figure 2: Forest plot showing sensitivity, specificity and negative predictive value of S100B ( $>1.27$ $\mu \mathrm{g} / \mathrm{L})$, arterial $\mathrm{pH}(<7.25)$ and $\mathrm{S} 100 \mathrm{~B}+\mathrm{pH}(>1.27 \mu \mathrm{g} / \mathrm{L}$ and/or $<7.25$ respectively) measurements in cord blood for the discrimination of neurological complications in neonates hospitalized in a neonatal intensive care unit (case group). *: $\mathrm{p}<0.05$.

Table 3: S100B and arterial $\mathrm{pH}$ values of eleven neonates with neurological complications. IVH: intraventricular haemorrhage; HIE: hypoxic ischaemic encephalopathy; PVL: periventricular leukomalacia. 


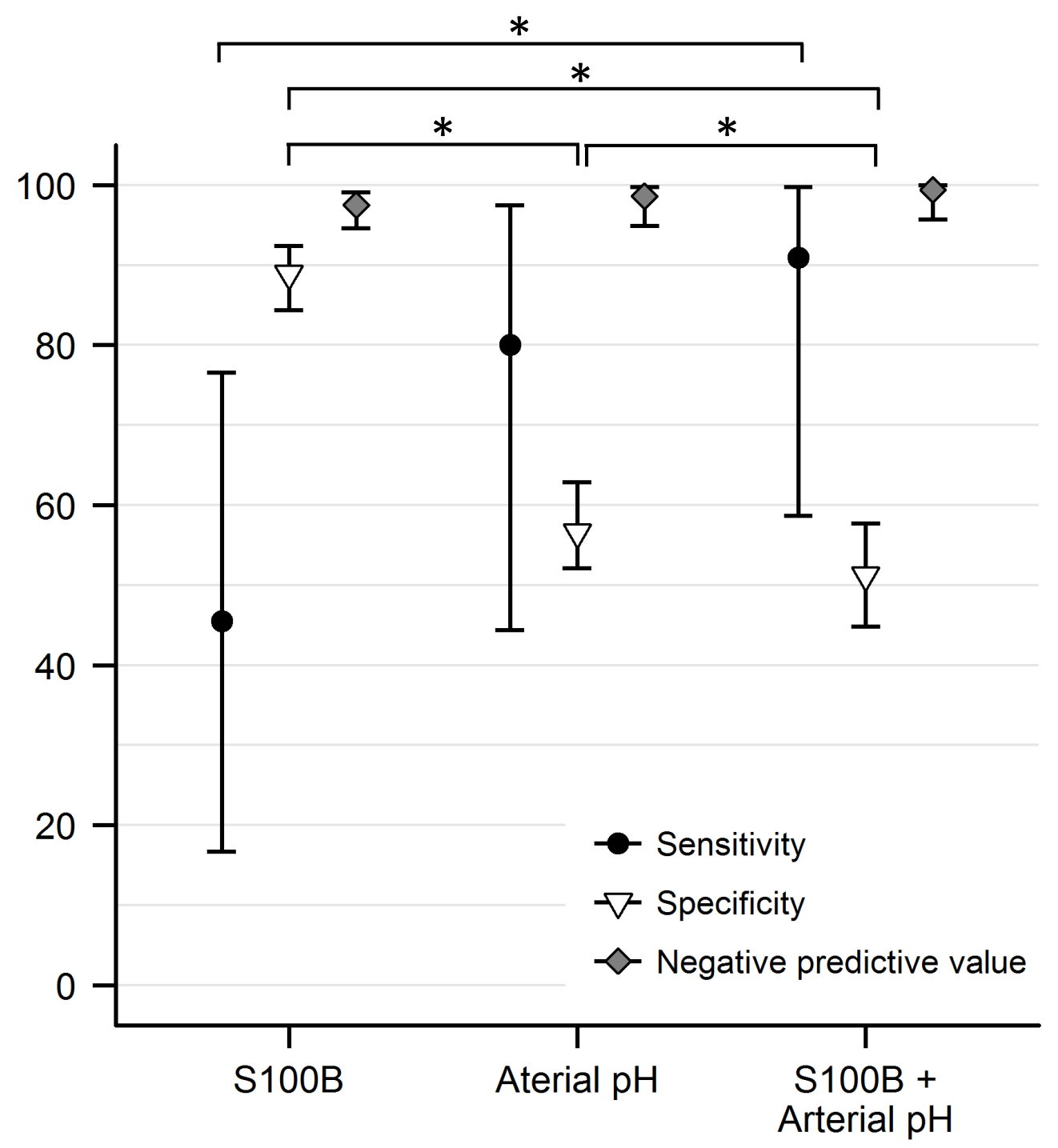

